\title{
JOSÉ DO PATROCÍNIO: UM ABOLICIONISTA NA FICÇÃO E NA VIDA
}

\author{
JOSÉ DO PATROCÍNIO: A ABOLITIONLIST IN FICTION AND IN LIFE
}

Marcos Teixeira Souza ${ }^{1}$

\section{Resumo}

Conhecido como um dos eminentes abolicionistas e jornalistas na campanha abolicionista do século XIX, José do Patrocínio também foi escritor, com três romances publicados. Em um deles, Motta Coqueiro ou a pena de morte, escrito em 1877, Patrocínio narra, por meio da personagem Balbina, a aflição da mulher negra, rememorando assim o sofrimento de Justina do Espírito Santo, mãe do abolicionista. É nesse momento que Historiografia e Literatura se confundem e se aproximam; e mostram José do Patrocínio como um abolicionista na ficção e na vida.

Palavras-chave: José do Patrocínio. Historiografia. Literatura. Mulher negra.

\begin{abstract}
Know as one of the eminent journalists ant abolitionists in the nineteenth century, in abolitionist campaign, José do Patrocínio was also a writer with three novels published. In one, Motta Coqueiro ou a pena de morte, Patrocínio narrates, through the character Balbina, the affliction of black woman, remembering the agony of Justina do Espírito Santo, mother of the abolitionist. That is when Historiography ant Literature approach; and show José do Patrocínio as an abolitionist in fiction and in life.
\end{abstract}

Keywords: José do Patrocínio. Historiography. Literature. Black woman.

\section{Introdução}

A exemplo de poucos, embora tenha conservado algumas inimizades políticas, José do Patrocínio aglutinou em si a simpatia de uma diversidade de grupos e indivíduos, os mais distantes socialmente, em uma época que marcar posição social era praxe. Tal proeza se deve, além de sua capacidade intelectual, a dois outros essenciais fatores: sua cor de pele e sua voz eloquente.

\footnotetext{
${ }^{1}$ Doutorado em Sociologia pela IUPERJ - Instituto Universitário de Pesquisas do Rio de Janeiro, Mestre em Letras e Ciências Humanas pela Unigranrio, Graduado e Licenciado em Letras pela UFRJ. E-mail: prof1marcos@hotmail.com
} 
Como bem apontou José Murilo de Carvalho, no prefácio da Campanha Abolicionista: coletânea de artigos (1996), Patrocínio era fruto do relacionamento de pai branco e mãe negra, o que o inseria em dois mundos distintos. Entre os abolicionistas e partidários da causa, Patrocínio era visto como o mais próximo da população afrodescendente, em razão da cor da pele do abolicionista campista. Viam nele um porta-voz autêntico no corpo e no espírito.

Por meio dos seus artigos nos jornais cariocas, Patrocínio defendia a Abolição diante da elite da época. Na tribuna parlamentar ou em praças públicas, discursava perante o povo o ideário abolicionista. E em ambos os espaços ele era efusivo nas palavras.

Neste sentido, o presente artigo visa a discutir, a partir da obra Motta Coqueiro ou a pena de Morte, o papel de José do Patrocínio como abolicionista, assinalando a proximidade entre Literatura e História; bem como enfatizando sua relevância para a Historiografia, diante de um Isabelismo reinante na História oficial, a qual subjuga ou minora o nome e a obra de José do Patrocínio na Literatura.

\section{A Literatura a serviço de uma causa}

O Brasil do século XIX foi palco de uma série de transformações sociais, culturais e políticas, fruto principalmente dos desdobramentos de momentos-chaves ocorridos no período: a Independência em 1822, a proibição do tráfico de escravos em 1850, a Abolição da Escravatura em 1888, e a Proclamação da República em 1889.

Neste contexto de amplas mudanças, a Literatura não esteve neutra neste processo ou à parte dele. Ao contrário, em determinadas ocasiões, foi um dos principais agentes condutores destas mudanças sociais. A poesia árcade ressonante nas ideias de independência política do Brasil, a poesia nacionalista de poetas românticos, como a de Gonçalves Dias, a poesia condoreira de Castro Alves, as prosas regionalistas, entre outros, expressaram o engajamento da Literatura nas discussões políticas em debate à época.

A compreensão de momentos-chaves na nação brasileira pelo olhar da História sem dúvida é um caminho oportuno e necessário. Contudo, a História, ou melhor, a Historiografia, restrita a documentos oficiais, em si mesma, como única fonte de pesquisa, tende a desconsiderar panoramas importantes.

Cabe dizer que nem toda literária oferece explicitamente dados e informações históricas. Contudo, há no interior dos romances, em maior ou menor grau, dependendo da obra, um diálogo mais ou menos próximo com o seu tempo, ou com um fato histórico. Neste sentido, Motta Coqueiro ou a pena de morte traz à cena o período colonial brasileiro, um 
capítulo da história brasileira que deixou profundas marcas sociais e identitárias no país. Como em outras obras literárias do período em que fora escrito Motta Coqueiro ou a pena de morte, a escravidão é descrita como uma nódoa na sociedade brasileira. Em alguns momentos as linhas da história se confundem com as linhas do romance. Em ambas as linhas, porém, é visível o ideário de Patrocínio em lutar pela abolição do trabalho escravo.

Quando se observa a produção literária na segunda metade do século XIX, especialmente a do período realista, vê-se uma literatura que tematiza questões sociais em pauta no cenário nacional, como a escravidão, a brasilidade, etc., não se limitando assim à esfera do lúdico.

A escrava Isaura (1841), de Bernardo Guimarães; A escrava (1846), de Gonçalves Dias; O Demônio Familiar (1856), de José de Alencar; As Vítimas Algozes (1869), de Joaquim Manuel Macedo; O mulato (1881), de Aluísio Azevedo; entre outras obras, sinalizaram uma literatura engajada no drama da Escravidão.

O romance era uma expressiva fonte de entretenimento da sociedade. Estampada em jornais, sob a forma de folhetim, muitos romances gozaram de popularidade, muito em razão da estrutura do enredo distribuído no folhetim. Cada capítulo era posto periodicamente, havendo no fim deste uma tensão na narrativa, que se resolveria somente com a leitura do capítulo posterior, que seria publicado em edição posterior. Por meio desta estrutura narrativa, provocadora de suspense no leitor, a fórmula rendia, como ainda rende, a receptividade de público, lembrando o que escreveu Antônio Hohlfeldt, em Pelas Veredas da Literatura Brasileira (1994), quanto a especificidades de público leitor, ou seja, circuito letrado, circuito popular (HOHFELDT, 1994, p. 85).

Por sua vez, Antônio Soares Amora, em Introdução à Teoria da Literatura (2006), ressalta o espectro cultural que se apresenta na escrita de um autor, entendo que um romance não se encontra dissociado de um ambiente cultural, permitindo assim uma interação autor/obra/leitor:

Que a obra reflete influências do ambiente cultural em que surge é, portanto, um fato fácil de compreender. (...) Mas se é certo dizer que o ambiente cultural exerce influência sobre o escritor e se expressa em sua obra, não é menos certo dizer que uma obra acaba também por exercer influência sobre o meio cultural que a envolve. (AMORA, 2006, p. 133)

A ponderação de Amora (2006) sobre a influência do ambiente cultural sobre um escritor e uma obra tem consonância se for pensado, por exemplo, um razoável de número de 
obras literárias na literatura da segunda metade do século XIX que aborda a escravidão, temática frequente nos jornais da época, tendo inclusive Patrocínio como um dos expoentes. De certa forma, Amora (2006), neste fragmento, problematiza o caráter social de uma obra literária, ou seja, a de dialogar com a realidade, não se circunscrevendo à esfera do lúdico. Há temáticas e dilemas sociais, muito presente no cotidiano da sociedade, que vão a um texto literário, e nele penetram os ecos da sociedade, que são tecidos na cosmovisão do autor. É compreensível esta dinâmica, porque o autor vive em uma sociedade. A figura de um autor encapsulado em um mundo à parte não partilha da realidade, em geral, dos autores brasileiros, muitos dos quais, estavam engajados em cargos políticos e/ou públicos, ou ainda, jornalistas e outras funções distintas na sociedade.

Pensando ainda no trecho de Amora (2006), tem-se o questionamento quanto à extensão de uma obra na sociedade, discussão que se relaciona ao pertencimento ou não de uma obra a um cânone. Pressupõe-se que uma obra canônica é aquela que, além de sua qualidade estético-literária, tenha exercido uma influência cultural. Contudo, é possível supor que o grau de prestígio social e cultural de uma obra em uma sociedade não se relaciona necessariamente a um cânone. Na Historiografia literária brasileira, assim como se deu (e se dá) em historiografias de outras nações, há obras que obtiveram renome, público e crítica, porém, sequer alcançaram o status de clássico ou canônico. Discutindo o esquecimento ou não de alguns autores negros na Literatura Brasileira do século XIX, Zahidé Lupinacci Muzart (1995), salienta como a questão da cor da pele foi um critério importante na Academia, embora não contivesse a entrada de autores negros e mulatos:

\footnotetext{
Como diz seu biógrafo, R. Magalhães Júnior, até hoje parece inexplicável a ausência de Cruz e Sousa na Academia. Mas se examinarmos a vida do poeta, a época, o país, isso não nos parecerá tão inexplicável. Em primeiro lugar, a questão da cor é importante, mas não é a razão primordial, pois Machado de Assis era mulato, mesmo disfarçando muito esse fato, e José do Patrocínio, negro. Mas é claro que não dá para esquecer que Cruz e Sousa era um negro (nascido filho de e cravos) num país que abolira a escravidão há apenas nove anos. (MUZART, 1995, p. 88).
}

Quando se menciona obras literárias do século XIX, cuja temática ou abordagem seja a escravidão, o nome e a obra de Castro Alves são tidos como clássicos. Por certo, Castro Alves é um nome que dignifica a literatura de qualquer nação, em razão de seu talento. Por outro lado, há obras esquecidas que, por muitos diversos, precisam ser recuperadas pelos pesquisadores e historiadores, diante dos conteúdos históricos contidos nestas. Neste ponto, é válido considerar que determinadas obras literárias foram propositalmente escondidas ou esquecidas, por não ser afinarem com o pensamento da elite à época. 
Escrito em 1877, Motta Coqueiro ou a pena de morte, o primeiro romance de José do Patrocínio, de três que escrevera, figurou à época da publicação, em folhetim, no Gazeta de Notícias, isto é, um dos principais jornais, como um romance de sucesso, tanto que ganhou uma versão em livro, segundo defende Renato César Möller (2007), em A fera de Macabu: memórias de um crime, uma pena de morte e uma maldição.

Contudo, para a geração pós-Patrocínio, de negros libertos até o presente momento, a obra permanece no esquecimento e neste vive. Algumas razões provavelmente colaboraram para isto: Patrocínio se via (e foi visto pelas gerações posteriores a ele) como eminente jornalista e abolicionista, e não como um romancista. Segundo: a obra era polêmica e politicamente incorreta para uma elite que procurava anular ou camuflar a existência de dilemas raciais presente na sociedade, como embranquecimento da nação, hierarquização racial, inferiorização do negro, degeneração do mulato, etc. E mais uma razão: Patrocínio romanceou em um período em contracenava com autores da envergadura de Machado de Assis e de Aluísio Azevedo, que começava a despontar como escritor; o que afastava, de certa forma, um pouco o nome de Patrocínio no âmbito das Letras como romancista.

Para Silviano Santiago, no prefácio da obra, na edição de 1977, o primeiro romance de Patrocínio se filia à tipologia de um romance de tese:

\footnotetext{
Desde o seu título, o texto de José do Patrocínio arvora características que o colocam dentro de categoria bem definida de obras: trata-se de romance de tese em que se pretende denunciar o processo infame que cerca a condenação à morte de um homem inocente. E, extrapolando o caso individual, o romance exige também a própria abolição da pena capital. (SANTIAGO, 1977, p. 11).
}

Esta concepção apresentada por Santiago (1977) sustenta assim uma plausibilidade para o esquecimento desta obra. Por se distanciar de uma literatura mais ficcional, o romance de tese, mais centrado na defesa em torno de uma ideia, teria secundarizado a exploração do aspecto ficcional no texto, proporcionando deste modo algumas críticas ao romance, e, ensejando, por tabela, um motivo possível para o esquecimento deste no cânone literário.

Além destas considerações, Patrocínio, na década de 1880, dedica-se com ardor à causa abolicionista, desviando a atenção do romancista que nele havia.

Valendo-se de um fato verídico ocorrido em Macabu, província de Campos, em 1852, Patrocínio, que nascera em 1853, na região, e que crescera ouvindo uma história popular acerca de um crime hediondo, anos depois, em sua juventude, com vinte e quatro anos, utiliza-se do evento, para obrar seu primeiro romance. 
O romance conta a história de Motta Coqueiro, influente fazendeiro do nortefluminense, que é tido como acusado pelo assassinato, com hediondez, de uma família de agregados, que viviam em suas terras. O motivo do crime seria um desentendimento, por causa de uma disputa de terra, entre o fazendeiro e o agregado, Francisco Benedito, que tinha esposa, três filhas moças, um filho moço, e mais duas crianças.

O bom convívio com o fazendeiro, que ofereça hospitalidade e trabalho em suas terras para a família de Francisco Benedito, é perdido com a desconfiança de que o fazendeiro afrontara a honra virginal de, pelo menos, uma das três filhas do agregado.

Enfatizando a formosura das três filhas de Benedito, o enredo sublinha a atração física e psicológica que elas exerciam sobre os homens da região. As três seriam alvo de conquista respectivamente por parte de três homens, que também alimentavam a desconfiança de que Motta Coqueiro teria abusado de, pelo menos, uma das moças.

A rede de intrigas e dúvidas sobre a suposta violação sexual é contracenada com o drama da escrava Balbina. No romance, Patrocínio descreve fisicamente Balbina como uma preta alta, corpulenta, de olhos maus, injetados de sangue, nariz grosso e beiços túmidos. (PATROCÍNIO, 1977, p. 67). Também é dito que tinha seus trinta e tantos anos. No aspecto psicológico, a personagem oscilava bom e mau humor, e detinha um temperamento forte (PATROCÍNIO, 1977, p. 67). Depois de ser expulsa da casa do fazendeiro, esta toma consciência do desvalor do negro na sociedade. Por ser a cuidadora e ama-de-leite do filho do fazendeiro, ela tinha em seu íntimo a crença de que era valorizada no seio familiar. A expulsão revela a ela o status quo da Escravidão, sendo o eito e a senzala seus novos lugares. A não-naturalização a estes lugares, contraposta à normalidade dos demais escravos ante ao cotidiano da Escravidão, faz da escrava Balbina uma denunciadora voz contra este regime, ressaltando o tom político e os ideais abolicionistas do autor, o jovem Patrocínio, figura então apenas promissora no cenário intelectual e político.

O drama de Balbina, ao longo da narrativa, instiga o leitor para a prosa; associado à dúvida sobre quem assassinara toda uma família, dúvida esta que pairava sobre o protagonista ou sua esposa, por ciúme, engendrando uma série de tensões no romance; além de outras secundárias, de cunho racial e social, que experimentariam alguns dos personagens na prosa.

Quando escreveu este romance, Patrocínio era tido ainda no cenário da Corte e da nação como um abolicionista em formação. Não que antes não fosse partidário da causa, mas que ainda não era reconhecido pela população como tal.

Ao firmar ou reafirmar sua voz abolicionista neste romance, por meio da personagem Balbina, Patrocínio se insere no rol dos defensores da Abolição de forma mais contundente, 
sendo esta obra um veículo influente em uma sociedade dividida entre partidários e contrários à Abolição.

\title{
Patrocínio: entre o Isabelismo e o Abolicionismo
}

Ao se utilizar do discurso literário, Patrocínio, com seu ímpeto pela causa abolicionista, vê-se na oportunidade de ousar em sua fala quanto a uma evidente dominação por parte de uma elite branca e detentora de latifúndios, contra uma população negra, reduzida a trabalhos forçados.

Assim, na voz de Balbina, Patrocínio não poupa palavras:

\begin{abstract}
- Hum, hum, os brancos? A negra criou o menino; era a mãe preta, e eles não deram nem um canto da casa grande para ela morar. Tomaram o menino das mãos da negra e meteram nelas a enxada. Depois o chicote fez feridas nas costas da feiticeira, e o menino nem olha mais para ela. A ririo machucada morde, a escrava desprezada mata. (PATROCÍNIO, 1977, p. 70).
\end{abstract}

Recorrente no texto, o abolicionista dá veemência a fala de Balbina contra a tirania da escravidão, feita pela mão do homem branco, retratando e ressaltando a natureza cruel do sistema escravagista:

\footnotetext{
- Não; a felicidade é para os brancos, a desgraça é para os cativos. Quando das costas de Balbina as feridas do chicote lançavam fumaça, como a boca aberta em dia de frio, a senhora brincava com o caçula doente, batendo-lhe com a ponta do dedo nos seus beicinhos vermelhos.

A mucama, parada junto dele, ria contente sem se lembrar que a sua parceira, cheia de dores, arribava o eito, gemendo no coração. Quando, de noite, o caçula tossia a sua doença, todos logo de pé corriam para ver e saber o que é que ele tinha, e quando de noite a escrava quase a morrer de raiva e de cansaço veio deitar-se na esteira da sua cama, só a pobre Carolina teve uma lágrima e um pouco d'água com que lavasse as feridas da infeliz. Não; a felicidade é para os brancos, a desgraça é só para os cativos. (PATROCÍNIO, 1977, p. 197).
}

Retomando Amora (2006), quando diz sobre a influência cultural sobre o escritor e a obra, é visível em Balbina uma alusão à mãe de Patrocínio, a escrava Justina do Espírito Santo.

Como constam nas biografias sobre o abolicionista, Magalhães Junior (1969) e Alves (2009), Patrocínio foi fruto do relacionamento de uma menina negra (escrava), que contava por volta dos treze anos de idade, com um padre branco, chamado José Carlos Monteiro, de cinquenta e quatro anos, que era também detentor de escravos, sendo a própria Justina uma de seus escravos. 
Em prefácio, José Murilo de Carvalho (1996) aventa a hipótese de que a luta abolicionista de Patrocínio o acompanha desde a infância:

Acima de tudo, estava sua paixão pela causa abolicionista, nascida talvez já em Campos no convívio com a mãe escrava. Esta paixão deu sentido a sua luta e a sua vida, sobretudo desde que passou a redator do jornal abolicionista, a Gazeta de Notícias, de Ferreira de Araújo, em 1877. (CARVALHO, 1996, p. 01).

O ambiente familiar de Patrocínio forjou em si um abolicionista à medida que se vê um pai senil, autoritário e senhor de escravos, que explorava o negro como objeto para lucro; e mulher negra como objeto de prazer sexual.

Assim, a hipótese enunciada por Carvalho (1996) ganha força ao visualizar no primeiro romance de Patrocínio, a redução de Balbina à coisa, a uma peça enxotada pelo senhor; e o papel dado a um padre vilão no segundo romance do abolicionista, Os retirantes (1879), conforme salientou um dos biógrafos de Patrocínio, Magalhães Junior (1969):

O novo romance muito daria o que falar. Talvez por ser filho de padre, Patrocínio era um anticlerical decidido e escolheu a figura de um sacerdote para o vilão de seu romance. Guardava inéditos os versos inspirados pelo horror de Guerra Junqueiro aos homens de batina, mas agora, em prosa, como que chamava a contas, através de tal personagem, o Cônego João Carlos Monteiro, morto três anos antes. (MAGALHÃES JÚNIOR, 1969, p.78).

Dentro dos romances ou fora dele, entre pai e mãe, a referência, para Patrocínio, era a mãe. Isso explica assim a atenção de Patrocínio, tanto na Literatura quanto em suas ações na imprensa, para o drama da mulher negra, como o ser mais frágil e vitimado pelo sistema escravocrata.

O tom denunciativo encontrado no romance Motta Coqueiro ou a pena de morte sobre a condição do negro, e, especialmente da mulher negra, por meio da personagem Balbina, é similar à veemência com que faz em artigos jornalísticos, como se pode constatar em determinadas passagens:

Sabe-se também que os senhores, querendo tirar todo o proveito do gado humano, ávidos de tirarem todo o lucro da pirataria à roda do berço, como se exprimia o grande Sales Torres Homem, expunham as mulheres desde os treze e quatorze anos à procriação. Há muitos fatos de indivíduos, que começando a vida apenas com cinco ou seis escravas boçais, legaram aos filhos escravaturas de mais de cem pessoas provenientes daqueles troncos. (PATROCÍNIO, 1996, p. 09). 
Referenciando a Lei 2.040, conhecida como Lei do Ventre Livre, de 28 de Setembro de 1871, Patrocínio evoca dura crítica contra aqueles que se aproveitavam do trabalho escravo: Anda pelas rodas de enjeitados a engolir esse lixo humano, criado pela lei de 28 de setembro, o ingênuo, que o senhor atira à rua para fazer do leite da mulher escrava a moeda, que sustenta a sua preguiça e o seu luxo (PATROCÍNIO, 1996, p. 25).

Ainda que na Literatura Patrocínio sinalizasse o drama de uma mulher negra, a exemplo do que ocorreu com a mãe do autor; ou ainda que na imprensa fizesse menção a este drama, persistia talvez no texto patrociniano um projeto maior que era a discussão do negro como ator importante e participante na construção da nação brasileira; o debate sobre a insustentabilidade do crescimento da nação sem a distribuição da riqueza, condenando assim o latifúndio, entre outras questões.

Diante de assuntos mais amplos, é compreensível que a defesa da mulher negra, vitimada pela estrutura escravocrata, tenha-se secundarizado em alguns momentos do texto do abolicionista campista, o que, no entanto, não significa dizer que Patrocínio se esvaiu de atenção sobre o tema. Tomando mais vulto seu bom relacionamento político com a princesa Isabel, as historiografias preferiram enfatizar a cena em que Patrocínio, genuflexo, beija as mãos da regente, coadjuvando o abolicionista, em detrimento de ocupar uma posição de destaque, ou mesmo, de figura central na luta pelos direitos da mulher negra.

Em seus artigos, Patrocínio tecia críticas ferozes ao governo imperial, desmoralizandoo por manter a escravidão no Brasil. De modo geral, as críticas à Princesa Isabel eram menos agudas do que aquelas dirigidas ao Imperador, que se revestiam de muita ousadia, conforme pode ser visto abaixo:

Que dirá a história da Regente, quando a vir, senhora delicada e mãe carinhosa, ensinando a fraternidade no paço a seus filhos e consentindo no Governo os co-réus dos assassinos que matam mulheres em Campos, espostejam cidadãos no Rio do Peixe, e levam a sanha a esporear cadáveres e a dar pontapés em crianças? (PATROCÍNIO, 1996, p. 120).

Quanto ao Imperador, o tom era severo, sem eufemismos: Feliz governo o do sr. $d$. Pedro II. A corrupção e a morte formam em torno dele uma impenetrável muralha. Quem não se deixa corromper morre! (PATROCÍNIO, 1996, p. 27). Em outro artigo, percebe-se a mesma ação intencional de macular o governo de D. Pedro II: Muito feliz é o Governo do sr. d. Pedro II. É preciso aceitá-lo tal como ele é. O trono do imperador tem como fundamento a escravidão. Não há resistir-lhe sem morrer. (PATROCÍNIO, 1996, p. 28). 
Apesar de algumas críticas à Princesa Isabel, Patrocínio nutria certa simpatia a ela, e assinatura da Lei Áurea, que era toda uma luta de vida e ideal de Patrocínio, fê-lo cativo a ela, ensejando posteriormente na criação da Guarda Negra, para proteger a regente.

No 13 de Maio de 1888, momento de glória de sua luta abolicionista, o gesto de beijar as mãos da princesa regente parece ter selado sua história como coadjuvante, e não como um dos protagonistas, já que era um abolicionista muito influente tanto para a população, quanto para a elite. E este lugar de coadjuvante se alocou, propositalmente ou não, nas memórias coletivas e nas historiografias oficiais, sendo inclusive Patrocínio pouco lembrado ou citado pelos movimentos negros, mesmo que tenha sido uma das vozes mais impactantes contra a escravidão na História do Brasil.

Se, por um lado, as historiografias oficiais tiram de Patrocínio um maior protagonismo no dia histórico, por outro lado, na Literatura, ou mais especificamente, nas poesias em forma de panfletos - que no dia da Abolição circularam ao redor do Senado, palco do ato da assinatura da Lei Áurea - devolvem à Patrocínio um papel de glória, de reconhecimento. Neste sentido, é oportuno o que escreve Venâncio em Panfletos Abolicionistas: o 13 de Maio em versos (2007):

\begin{abstract}
Há muito se sabe que a poesia foi uma arma na luta contra a escravidão. Poucos, porém, têm notícia de que ela também cristalizou as manifestações de alegria, fazendo um chamado coletivo ao congraçamento e à união frente à transformação ocorrida no 13 de maio. Em várias partes do Brasil, poemas foram escritos e publicados em papéis coloridos, daí migrando para jornais, alcançando um público bastante vasto, enraizando os sentimentos de justiça e humanitarismo representados pelo fim da escravatura. Os poemas aqui publicados são panfletos, na medida que expressam um posicionamento político e retratam a vitória de um movimento de opinião pública. (VENÂNCIO, 2007, p. 13).
\end{abstract}

Nos poemas elencados em Panfletos Abolicionistas: o 13 de Maio em versos (2007), ainda que a Princesa Isabel tenha sido alvo de poesias, o nome de Patrocínio é poetizado, associando-o à figuras marcantes na cultura brasileira: a Tiradentes, num poema: E assim da liberdade o santo tirocínio / A Tiradentes fez igual a Patrocinio. (Oliveira E. Silva). Em outro poema, a Cristo: Mais feliz do que Christo, ó Patrocinio / - Da nação escrava tu quebraste a cruz! (Guil Mar.).

Outro poema dirigido a José do Patrocínio que chama atenção é o assinado pela Baronesa de Mamanguape (talvez um pseudônimo), denominado A escrava. Poetizando o drama da mulher negra, a poetisa remete, intencionalmente ou não, ao sofrimento da escrava Balbina, do primeiro romance de Patrocínio, o Motta Coqueiro ou a pena de morte, construindo assim uma intertextualidade. Além disso, este poema é oportuno para lembrar o 
olhar de Patrocínio para com o drama da mulher negra, a exemplo da mãe do abolicionista e milhões de outras mulheres, que foram martirizadas por senhores, os quais se achavam no direito de espancá-las, ou abusar sexualmente delas.

O nome de Patrocínio assim se liga ao universo literário, seja pela sua própria obra literária, seja por outras que a ele fazem referência. Neste sentido, desconsiderar o discurso literário significa abrir mão de entender com mais amplitude os fatos envoltos em torno da luta abolicionista.

\section{Considerações finais}

Ao escrever Motta Coqueiro ou a pena de morte, fica patente que Patrocínio não se valeu apenas um fato verídico ocorrido no norte-fluminense, mas que, sob o pano de fundo deste fato, discursou, nas páginas do romance, em favor da Abolição dos escravos, desnudando em seu texto todo o horror intrínseco à escravidão.

Não se restringindo a só refutar a escravidão, uma leitura mais atenta, mostra que na obra se encontra uma série de memórias do autor: a lembrança da dor de sua mãe, metaforizada na personagem Balbina, o conflito amoroso de cunho racial, presente no personagem Manuel João, que fora também seu conflito, por estar apaixonado por uma moça branca, sendo ele mestiço; entre outras memórias, que trazidas a lume pela via literária, colaboram para entender o Abolicionista.

Obviamente não se quer dizer que a leitura deste romance revelará, por completo, Patrocínio. No entanto, ao deixar de ler e contemplar Motta Coqueiro ou a pena de morte perde-se a oportunidade de ver um Patrocínio que se dedicou à luta abolicionista, tanto na ficção, quanto na vida, uma vida que não se esmoreceu aos desafios de seu tempo.

\section{Referências}

ALVES, Ueliton Farias. José do Patrocínio: a imorredoura cor do bronze. Rio de Janeiro: Garamond, 2009.

AMORA, Antônio Soares. Introdução à Teoria da Literatura. São Paulo: Cultrix, 2006.

CARVALHO, José Murilo de. Prefácio. In: PATROCÍNIO, José do. Campanha Abolicionista: coletânea de artigos. Rio de Janeiro: Fundação Biblioteca Nacional, 1996.

HOHLFELDT, Antônio. Pelas veredas da Literatura Brasileira. Porto Alegre: EDIPUCRS, 1994. 
MAgAlHÃes JUNIOR, Raimundo. A vida turbulenta de José do Patrocínio. Rio de Janeiro: Editora Sabiá, 1969.

MÖLLER, Renato César. A fera de Macabu: memórias de um crime, uma pena de morte e uma maldição. 1995. Tese (Doutorado) - Universidade Estadual do Rio de Janeiro-UERJ, Rio de Janeiro, 2007.

MUZART, Zahidé. Lupinacci. A questão do cânone. Anuário de Literatura, Florianópolis, n.3, p. 85-94, 1995.

PATROCÍNIO, José do. Campanha Abolicionista: coletânea de artigos. Rio de Janeiro: Fundação Biblioteca Nacional, 1996.

Motta Coqueiro ou a pena de morte. Rio de Janeiro: Livraria Francisco Alves/SEEC, 1977.

SANTIAGO, Silviano. Desvios da ficção. In: PATROCÍNIO, José do. Motta Coqueiro ou a pena de morte. Rio de Janeiro: Livraria Francisco Alves/SEEC, 1977.

VENÂNCIO. Renato Pinto. Panfletos Abolicionistas: o 13 de Maio em versos. Belo Horizonte: Secretaria de Estado de Cultura de Minas, 2007. 